\title{
Neurokinin 3 Receptor Antagonism: A Novel Treatment for Menopausal Hot Flushes
}

\author{
Manish Modi Waljit S. Dhillo \\ Section of Endocrinology and Investigative Medicine, Imperial College London, London, UK
}

\section{Keywords}

Neurokinin B · Neurokinin 3 receptor · Menopause $\cdot$ Hot flushes · Review

\begin{abstract}
Menopause is associated with significant symptomatic burden, with approximately two-thirds of postmenopausal women suffering from vasomotor symptoms, hot flushes, and night sweats. The mainstay of treatment for hot flushes continues to be hormone replacement therapy. However, as hormone replacement therapy is contraindicated in some cases, alternative, efficacious treatment options are also required. Hot flushes are thought to arise as a result of significant changes in the neuroendocrine circuitry underpinning the reproductive axis during menopause. This includes reduced circulating ovarian oestrogens, hypersecretion of gonadotropins, and increased expression of kisspeptin and neurokinin $B$ (NKB) within the infundibular nucleus of the hypothalamus. In recent years, NKB, predominantly acting via the neurokinin 3 receptor (NK3R), has emerged as an important player in the development of menopausal hot flushes. Antagonism of NK3R has garnered much interest as a novel therapeutic target to help ameliorate hot flush symptoms. Improvements in hot flush frequency, severity, and quality of life have been demonstrated in a number of clini-
\end{abstract}

cal trials using novel NK3R antagonists in postmenopausal women. Within this review, we will explore the growing body of evidence supporting antagonism of NK3R as a potentially promising treatment for menopausal hot flushes.

(c) 2018 S. Karger AG, Basel

\section{Introduction to the Menopausal Hot Flush}

Menopause and the perimenopausal state are associated with significant symptomatic burden, with approximately two-thirds of women suffering from vasomotor symptoms, hot flushes, and night sweats. These symptoms have been reported to persist for as long as 15 years in one-fifth of women, with $10 \%$ describing them as intolerable [1]. A hot flush has been described as a subjective sensation of extreme heat associated with objective signs of cutaneous vasodilation and a subsequent drop in core temperature. This thermoregulatory response to perceived warmth occurs due to inappropriate recruitment of heat dissipation effectors [2]. It has been postulated that this altered thermoregulatory response arises as a result of abrupt changes in hormone concentrations typically associated with human menopause, including oestrogen deficiency. Oestrogen plays an important role in body temperature regulation, as ovariectomy has been

\section{KARGER}

(c) 2018 S. Karger AG, Basel

E-Mail karger@karger.com

www.karger.com/nen
Prof. Waljit S. Dhillo

Department of Investigative Medicine, Imperial College London

6th Floor Commonwealth Building, Hammersmith Hospital, Du Cane Road

London W12 0NN (UK)

E-Mailw.dhillo@imperial.ac.uk 
shown to increase tail skin temperature in rats [3]. This can subsequently be reduced by oestrogen replacement [4]. Rapid withdrawal of oestrogen, as seen in premenopausal women undergoing bilateral oophorectomy, has been shown to significantly increase the risk of developing hot flushes compared to menopausal women, suggesting that the rate in change of circulating oestrogen levels is also an important factor to consider [5].

Hormonal and neuroendocrine changes associated with menopause are thought to be responsible for the inappropriate activation of heat dissipation effectors and the subjective hot flush [6]. These thermoregulatory changes within the hypothalamus will persist until the individual becomes acclimatised to low circulating oestrogen levels, after which hot flushes may gradually subside. However, there is significant variability in the patterns of hot flushes, and frequent vasomotor symptoms may persist for more than 7 years [7].

\section{Current Treatment Options and Challenges}

Conventionally, hormone replacement therapy has been widely utilised to help restore hormonal balance and therefore ameliorate hot flushes. However, hormone replacement therapy may not be suitable in women with increased risk of cardiovascular disease, thromboembolic disease, or increased risk of certain cancer types, such as breast and endometrial cancer [8]. Therefore, its efficacy is limited by the duration of treatment recommended and whether any contraindications are present which prohibit its use [9]. Alternative treatment options include selective serotonin reuptake inhibitors, gabapentin, cognitive behavioural therapy, herbal remedies, acupuncture, as well as diet and lifestyle modifications [10]. In light of the significant symptom burden experienced by postmenopausal women due to hot flushes, the need for novel agents has been a focus of research in recent years. In addition to menopause, hot flush symptoms are also commonly experienced by women who have received hormone deprivation therapy for breast cancer. However, oestrogen replacement is generally not advised in these cases [11], so alternative, efficacious treatment options are required.

\section{Neurokinin B as a Novel Therapeutic Target}

Understanding of the neuroendocrine pathways implicated in the regulation of reproduction and sex hormone secretion has advanced significantly in the last 15 years and has therefore aided in the identification of potential novel therapeutic targets for further research. Such targets include the neurokinin B (NKB) signalling pathway, which is thought to be implicated in the development of hot flushes and can therefore be modulated to attenuate symptoms.

$\mathrm{NKB}$, a hypothalamic neuropeptide, has emerged as a key player within the regulation of the "normal" female reproductive axis. NKB is a member of the tachykinin family of peptides, encoded by the TAC3 gene in humans. NKB preferentially binds to the neurokinin 3 receptor (NK3R), encoded by TACR3. Individuals with homozygous loss-of-function mutations in either TAC3 or TACR3 have been shown to exhibit hypogonadotropic hypogonadism phenotypically, with failure of pubertal progression. Affected individuals also show evidence of failure of normal intrauterine and perinatal activation of the reproductive axis [12]. This evidence suggests that $\mathrm{NKB} / \mathrm{NK} 3 \mathrm{R}$ signalling plays a crucial role in the central neuroendocrine control of human reproduction.

\section{Regulation of the Hypothalamic-Pituitary-Gonadal Axis}

In order to further explore novel therapeutic targets, it is important to first understand the neuroendocrine circuitry underpinning the reproductive axis and how this is altered during menopause.

The hypothalamic-pituitary-gonadal axis is critical in regulating reproductive function. Gonadotropin-releasing hormone $(\mathrm{GnRH})$ is an integral component of the hypothalamic-pituitary-gonadal axis and is expressed by GnRH neurons within the arcuate nucleus (Arc), or infundibular nucleus in humans, of the hypothalamus. Pulsatile delivery of $\mathrm{GnRH}$ to gonadotrope cells in the anterior pituitary gland stimulates the release of follicle-stimulating hormone (FSH) and luteinising hormone (LH). Secretion of LH and FSH triggers downstream release of sex hormones, including oestradiol and testosterone, from the gonads. Increases in sex steroid concentrations will exhibit a negative feedback effect on GnRH neurons, resulting in suppression of GnRH secretion. The Arc has been recognised as the nodal point for controlling this negative feedback effect as well as regulating the pulsatile secretion of $\mathrm{GnRH}$.

In recent years kisspeptin, encoded by the Kiss 1 gene, has been identified as a crucial activator of GnRH neurons within the Arc, driving the secretion of GnRH from 
fibres in the median eminence and supporting the generation of LH pulses [13]. Within the Arc, kisspeptin colocalises with NKB and dynorphin (Dyn) to form the "KNDy" neurons. NKB and Dyn are thought to act autosynaptically on kisspeptin neurons in the Arc via neurokinin 3 and Dyn receptors to synchronise and shape the pulsatile secretion of kisspeptin [14]. The secretion of kisspeptin and the expression of NKB, NK3R, and Dyn are negatively regulated by the effect of circulating oestrogen and subsequently result in a reduction of $\mathrm{GnRH}$ and thereby LH secretion. This negative feedback pathway helps maintain normal reproductive physiology in women of child-bearing age.

\section{Neuroendocrine Changes in Menopause}

Human menopause is typically characterised by virtually absent ovarian follicles and reduced production of ovarian oestrogen and progesterone. Due to lack of negative feedback from circulating oestrogen, there is increased secretion of LH and FSH from the anterior pituitary gland [15]. The increase in LH secretion seen is likely mediated by increased secretion of $\mathrm{GnRH}$ and altered activity of neurons expressing Kiss1, NKB, and Dyn in the infundibular nucleus [16]. Rance and colleagues have significantly expanded our understanding of postmenopausal changes within the reproductive axis through both human and animal work and helped elucidate potential mechanisms for the development of hot flushes. Postmortem examination of hypothalamic tissue from postmenopausal women reveals neural hypertrophy in the hypothalamic infundibular (Arc) nucleus. There is strong evidence that ovarian failure causes an increase in kisspeptin neuronal size and gene expression [17]. Similarly, marked increases in hypothalamic NKB gene expression are also seen in postmenopausal women [18]. The kisspeptin and NKB neuronal hypertrophy in the Arc and consequent increased gene expression observed in menopause are likely a consequence of loss of negative feedback from oestrogen. It has been demonstrated that these neuronal changes can be induced by ovariectomy in young monkeys and that normal neuronal size and gene expression can be restored with oestrogen replacement [19]. Similarly, replacement of oestrogen has been shown to decrease the cell size and dendritic spine density of KNDy neurons in ovariectomised mice [20]. In the absence of oestrogen, increased kisspeptin and NKB signalling will result in hypersecretion of GnRH.

\section{Involvement of NKB/NK3R Signalling in Menopausal Hot Flushes}

In light of the marked changes in kisspeptin and NKB expression demonstrated during menopause, further studies have also explored their role in the development of hot flushes.

Kisspeptin-expressing neurons within the Arc, which also coexpress $\mathrm{NKB}$, project some of their axons to the median preoptic area of the hypothalamus (mPOA). The median preoptic nucleus and the adjacent $\mathrm{mPOA}$ have emerged as the central hub of control of thermoregulation in mammals [21], receiving input from, and projecting to, the autonomic thermoregulatory pathway. The median preoptic nucleus has been demonstrated to express NK3R mRNA [22], the primary receptor for NKB. Ablation of KNDy neurons in the Arc of rats has been shown to decrease tail skin temperature through reduced cutaneous vasodilation, an important effector of heat dissipation [23]. These findings are consistent with the hypothesis that KNDy neurons participate in the development of menopausal hot flushes, as both cutaneous vasodilation and reduced core temperature are hallmarks of hot flush physiology [6]. In addition, KNDy neurons likely play an important role in oestrogen-mediated modulation of body temperature. Ovariectomised rats demonstrate elevated core body temperature, but only at warmer ambient temperatures. This elevation in body temperature can be lowered with oestrogen replacement [24]. However, following ablation of KNDy neurons, the core temperature of ovariectomised rats could not be altered by oestrogen replacement [23].

To further elucidate the role of NKB/NK3R signalling in the development of hot flushes, a selective NK3R agonist, senktide, has been administered to ovariectomised, oestrogen-primed rats. Central (intracerebroventricular) administration of senktide has been shown to induce c-Fos expression, a marker of neuronal activity, in the mPOA and Arc [25]. As the mPOA is part of the neural circuitry involved in thermoregulation, increased neuronal activity there may represent activation of heat dissipation effectors. This is further evidenced by infusion of senktide into the rat median preoptic nucleus, which has been shown to reduce core body temperature without thermoregulatory failure or a reduction in cold-induced thermogenesis [26]. The reduction in core body temperature is similar to that seen during hot flush episodes and occurs in response to activation of NK3R, suggesting that the $\mathrm{NKB} / \mathrm{NK} 3 \mathrm{R}$ signalling pathway is implicated in the pathophysiology of hot flushes. Furthermore, subcutane- 
ous injection of an NK3R agonist in ovariectomised mice has been shown to cause an acute rise in skin temperature but a reduction in core temperature consistent with activation of heat dissipation effectors. These changes were reduced with the administration of oestradiol, suggesting that oestrogen lowers the sensitivity of central thermoregulatory pathways to NK3R activation [27].

Padilla et al. [2] recently explored the relationship between kisspeptin neurons, the mPOA, NKB/NK3R signalling, and the generation of hot flushes through a series of studies using genetic and viral technologies in mice. Artificial activation of the kisspeptin neurons in the Arc has been shown to induce an increase in tail skin temperature in male and female mice alike, along with an increase in c-Fos expression in the median preoptic nucleus. The increase in tail skin temperature noted is thought to be part of a heat dissipation response, whereby cutaneous vasodilation results in a drop in core body temperature. The kisspeptin neurons were noted to be more sensitive to activation after ovariectomy in female mice, suggesting that hot flush susceptibility may be altered in oestrogen withdrawal states, such as menopause. However, infusion of neurokinin receptor antagonists (targeting NK1R, NK2R, and NK3R) into the rat mPOA prior to activation of the kisspeptin neurons completely abolished the increase in tail skin temperature previously seen. These data insinuate that kisspeptin neurons may initiate the hot flush response via NKB within the mPOA and that modulation of this signalling pathway may present a novel treatment option for hot flushes.

To translate these studies to humans, Jayasena et al. [28] have previously performed a randomised, doubleblind, placebo-controlled study in healthy premenopausal women, using peripheral intravenous infusion of $\mathrm{NKB}$ to mimic the increased NKB expression that is naturally present in women after menopause. Participants were asked to subjectively report any symptoms experienced during infusion of either vehicle or NKB as the primary endpoint, but not advised specifically about hot flush symptoms so as to minimise reporting bias. NKB infusion induced hot flushes in premenopausal women that were very similar to those experienced by menopausal women, as evidenced by symptom reporting and objective physiological increases in heart rate and skin temperature during the subjective hot flush episodes. Furthermore, a transethnic meta-analysis of three genome-wide association studies has demonstrated that hot flushes in women aged 50-79 years correlated with the presence of single nucleotide polymorphisms on chromosome 4 in the TACR3 locus, the gene that codes NK3R. This postulated

Neurokinin 3 Receptor Antagonism for

Menopausal Hot Flushes that genetic variation in TACR3 may contribute to the risk of developing hot flushes [29], again implicating the $\mathrm{NKB} / \mathrm{NK} 3 \mathrm{R}$ signalling pathway in the aetiology of menopausal hot flushes. However, the exact mechanism by which these genetic variants are related to the increased risk of vasomotor symptoms is yet to be elucidated, as none of the single nucleotide polymorphisms identified were located in the coding area of the receptor.

\section{Antagonism of NKB/NK3R Signalling as a Novel Treatment for Menopausal Hot Flushes}

As stimulation of $\mathrm{NKB} / \mathrm{NK} 3 \mathrm{R}$ signalling has been shown to induce hot flushes, antagonism of this signalling pathway naturally emerges as a potential therapeutic target to help ameliorate these symptoms [30]. As mentioned previously, central antagonism of NKB signalling within the mPOA of rats can prevent the physiological hot flush response that is generated by kisspeptin neuron activation in the Arc [2]. This can be translated to a human model, whereby the hot flush response can be attenuated by antagonism of neurokinin receptors.

Prague et al. [31] performed a randomised, doubleblind, placebo-controlled, crossover trial of an oral NK3R antagonist (MLE4901) in a proof of concept study. They recruited menopausal women experiencing at least 7 hot flushes within a $24-\mathrm{h}$ period and showed that women receiving an oral NK3R antagonist over a 4-week period had an overall $73 \%$ reduction in hot flush frequency (with a $45 \%$ reduction above placebo), as measured by subjective reporting and concordant skin conductance monitoring to objectively measure hot flushes. Further analysis of these data identified that these symptomatic improvements largely occurred within 3 days of treatment and persisted throughout the 4-week trial period. This highlights that there is rapid and sustained relief from hot flushes with NK3R antagonism, without the need for any oestrogen exposure [32]. Skorupskaite et al. [33] similarly observed a reduction in the frequency and severity of hot flushes and a reduction in LH secretion after administering MLE4901 to symptomatic postmenopausal women. Infusion of fezolinetant (ESN364), an alternative NK3R antagonist, has also been shown to reduce hot flush frequency overall by $93 \%$ in women experiencing more than 49 moderate to severe hot flushes per week (with a $46 \%$ reduction compared to placebo). As secondary endpoints, improvements in sleep quality, quality of life, and personal/professional productivity were noted as a result of drug therapy [34]. Pawsey et al. [35] recently performed 


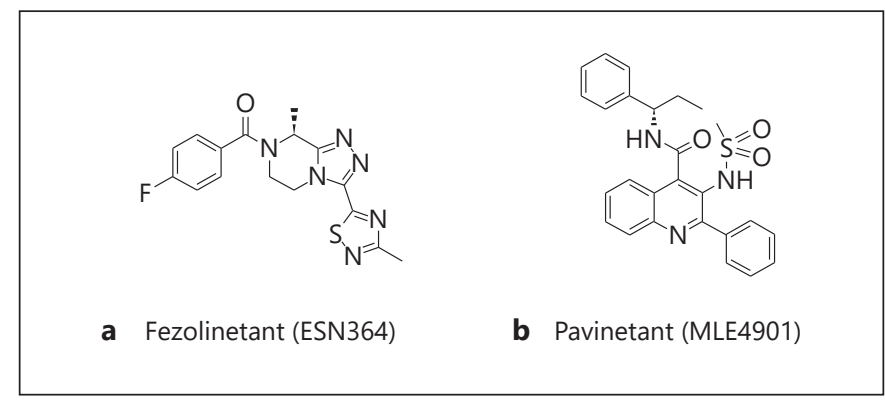

Fig. 1. Molecular structure of the selective neurokinin 3 receptor antagonists fezolinetant [36] (a) and pavinetant [37] (b).

a randomised, double-blind, placebo-controlled trial administering increasing doses of NT-814, an oral, dual NK1R and NK3R antagonist. In healthy women aged 4065 years experiencing 7-20 hot flushes per day, NT-814 produced an up to $84 \%$ reduction in hot flush frequency and an up to $81 \%$ reduction in nighttime awakenings compared to placebo (37 and $32 \%$ reduction, respectively). These effects were apparent on the first day of treatment and persisted for up to 14 days.

Further long-term studies are required to establish the safety profile of NK3R antagonists as for any new class of drug. While no serious adverse effects have been reported to date, Prague et al. [31] have reported an asymptomatic rise in transaminase concentrations in a small subgroup of participants receiving MLE4901 that was not associated with a rise in bilirubin. After assessment of the clinical risks and benefits, the development of MLE4901 for use in the treatment of hot flushes was discontinued by the parent biopharmaceutical company in November 2017. However, there have been no reported concerns regarding liver toxicity with either fezolinetant or NT-814. At the molecular level, there is no obvious structural similarity between fezolinetant [36], MLE4901 [37] (Fig. 1), and NT814 (structure yet to be published), so the transient elevation in transaminases reported with MLE4901 may be an idiosyncratic effect related to its chemical structure rather than a class effect of NK3R antagonists as a whole.

\section{Other Implications of NK3R Antagonism}

In addition to attenuation of vasomotor symptoms, pharmacological antagonism of NK3R has emphasised the crucial role that $\mathrm{NKB} / \mathrm{NK} 3 \mathrm{R}$ signalling plays in the physiological regulation of the reproductive axis. Fezolinetant has been shown to significantly lower plasma LH and oestradiol levels in gonadectomised ewes and castrated nonhuman primates [38]. Reduced levels of oestradiol during the follicular phase resulted in the absence of the LH surge and a failure of a subsequent luteal phase rise in plasma progesterone. When translated to humans, fezolinetant [39] and MLE4901 [40] reduced LH pulsatility and suppressed basal LH and oestradiol levels when administered to healthy women during the follicular phase. These hormonal changes resulted in delayed ovulation, decreased endometrial thickening, impeded follicular maturation, and prolonged menstrual cycle. MLE4901 has also been shown to suppress follicle growth, likely as a consequence of suppressed basal LH secretion [41]. In women with polycystic ovary syndrome, who exhibit hypersecretion of LH, MLE4901 specifically reduced LH pulse frequency and, subsequently, basal serum LH and testosterone levels [42]. These clinical studies suggest that NK3R antagonists can modulate the reproductive axis in women of childbearing potential and could therefore have potential implications on the management of dysfunctional sex hormone-dependent diseases such as polycystic ovary syndrome, uterine fibroids, and endometriosis. NT-814 has also been shown to produce a rapid and sustained reduction in testosterone in healthy male volunteers and may therefore also modulate the reproductive axis of women in a fashion similar to the other NK3R antagonists [43].

In order to target the central (hypothalamic) pathways that govern thermoregulation and regulation of the reproductive axis, it is imperative that any potential therapeutic agent be able to penetrate the blood-brain barrier. Using human positron emission tomography data, NT814 (formerly known as GSK1144814), a dual antagonist of NK1R and NK3R, has been shown to enter the human brain and achieve long-lasting and sustained NK1R occupancy in healthy male volunteers [44]. As there are no current neurokinin 3 positron emission tomography ligands, the NK3R occupancy has been inferred from the NK1R occupancy based on in vitro affinity ratios. It has been postulated that the dose of NT-814 required to occupy $95 \%$ of NK1Rs will occupy approximately $67 \%$ of the NK3Rs and will therefore antagonise NKB/NK3R signalling centrally after oral administration.

\section{Conclusion}

The current literature provides strong evidence that NK3R antagonism is a promising target for further pharmacological studies, with promising data on improve- 
ment in the frequency, severity, and impact of hot flushes. The implications of these studies extend beyond the scope of menopause and could provide a useful treatment option in patients experiencing hot flushes as a consequence of oestrogen deprivation therapy in breast cancer and androgen deprivation therapy in prostate cancer [45]. Further prospective clinical studies will provide a stronger evidence base for targeting the NKB/NK3R signalling pathway in the treatment of hot flush symptoms in a variety of patient populations and will help establish the safety profile for NK3R antagonists. There is also the potential to target the $\mathrm{NKB} / \mathrm{NK} 3 \mathrm{R}$ signalling pathway in the management of dysfunctional sex hormone-dependent diseases, which will need to be explored further too.

\section{Acknowledgements}

We would like to thank Dr. Mike Trower for providing unpublished information on NT-814 for the purpose of this paper. We would also like to thank Dr. Graeme Fraser for his advice during the revision of the manuscript.

\section{Statement of Ethics}

The authors have no ethical conflicts to disclose.

\section{Disclosure Statement}

M. Modi has no conflicts of interest to declare. W.S. Dhillo has undertaken consultancy work with Myovant Sciences, Inc. and KaNDy therapeutics. W.S. Dhillo has filed a patent for the use of NK3R antagonists in menopausal flushing.

\section{Funding Sources}

M. Modi is funded by an NIHR Academic Clinical Fellowship. W.S. Dhillo is funded by an NIHR Research Professorship.

\section{Author Contributions}

M. Modi researched and prepared the manuscript. W.S. Dhillo edited the manuscript for important intellectual content.

\section{References}

1 Stearns V, Ullmer L, López JF, Smith Y, Isaacs C, Hayes D. Hot flushes. Lancet. 2002 Dec; 360(9348):1851-61

2 Padilla SL, Johnson CW, Barker FD, Patterson MA, Palmiter RD. A Neural Circuit Underlying the Generation of Hot Flushes. Cell Reports. 2018 Jul;24(2):271-7.

3 Kobayashi T, Ushijima O, Chen JT, Shiraki M, Ohta T, Kiyoki M. Basal tail skin temperature elevation and augmented response to calcitonin gene-related peptide in ovariectomized rats. J Endocrinol. 1995 Sep;146(3): 431-7.

4 Bowe J, Li XF, Kinsey-Jones J, Heyerick A, Brain S, Milligan S, et al. The hop phytoestrogen, 8-prenylnaringenin, reverses the ovariectomy-induced rise in skin temperature in an animal model of menopausal hot flushes. J Endocrinol. 2006 Nov; 191(2):399-405.

5 Gallicchio L, Whiteman MK, Tomic D, Miller KP, Langenberg P, Flaws JA. Type of menopause, patterns of hormone therapy use, and hot flashes. Fertil Steril. 2006 May;85(5): 1432-40.

6 Rance NE, Dacks PA, Mittelman-Smith MA, Romanovsky AA, Krajewski-Hall SJ. Modulation of body temperature and LH secretion by hypothalamic KNDy (kisspeptin, neurokinin $\mathrm{B}$ and dynorphin) neurons: a novel hypothesis on the mechanism of hot flushes. Front Neuroendocrinol. 2013 Aug;34(3):211-27.

7 Avis NE, Crawford SL, Greendale G, Bromberger JT, Everson-Rose SA, Gold EB, et al.;
Study of Women's Health Across the Nation. Duration of menopausal vasomotor symptoms over the menopause transition. JAMA Intern Med. 2015 Apr;175(4):531-9.

8 Marjoribanks J, Farquhar C, Roberts H, Lethaby A, Lee J. Long-term hormone therapy for perimenopausal and postmenopausal women. Cochrane Database Syst Rev. 2017 Jan;1:CD004143.

9 Rossouw JE, Anderson GL, Prentice RL, LaCroix AZ, Kooperberg C, Stefanick ML, et al.; Writing Group for the Women's Health Initiative Investigators. Risks and benefits of estrogen plus progestin in healthy postmenopausal women: principal results From the Women's Health Initiative randomized controlled trial. JAMA. 2002 Jul;288(3):321-33.

10 McGarry K, Geary M, Gopinath V. Beyond Estrogen: Treatment Options for Hot Flashes. Clin Ther. 2018 Oct;40(10):1778-86.

11 Santen RJ, Stuenkel CA, Davis SR, Pinkerton JV, Gompel A, Lumsden MA. Managing Menopausal Symptoms and Associated Clinical Issues in Breast Cancer Survivors. J Clin Endocrinol Metab. 2017 Oct;102(10):3647-61.

12 Topaloglu AK, Reimann F, Guclu M, Yalin AS, Kotan LD, Porter KM, et al. TAC3 and TACR3 mutations in familial hypogonadotropic hypogonadism reveal a key role for Neurokinin B in the central control of reproduction. Nat Genet. 2009 Mar;41(3):354-8.

13 Han SY, McLennan T, Czieselsky K, Herbison AE. Selective optogenetic activation of arcuate kisspeptin neurons generates pulsatile luteinizing hormone secretion. Proc Natl Acad Sci USA. 2015 Oct;112(42): 13109-14.

14 Navarro VM, Gottsch ML, Chavkin C, Okamura H, Clifton DK, Steiner RA. Regulation of gonadotropin-releasing hormone secretion by kisspeptin/dynorphin/neurokinin B neurons in the arcuate nucleus of the mouse. J Neurosci. 2009 Sep;29(38):11859-66.

15 Hansen KR, Knowlton NS, Thyer AC, Charleston JS, Soules MR, Klein NA. A new model of reproductive aging: the decline in ovarian non-growing follicle number from birth to menopause. Hum Reprod. 2008 Mar; 23(3):699-708.

16 Rance NE. Menopause and the human hypothalamus: evidence for the role of kisspeptin/ neurokinin $B$ neurons in the regulation of estrogen negative feedback. Peptides. 2009 Jan; 30(1):111-22.

17 Rometo AM, Krajewski SJ, Voytko ML, Rance NE. Hypertrophy and increased kisspeptin gene expression in the hypothalamic infundibular nucleus of postmenopausal women and ovariectomized monkeys. J Clin Endocrinol Metab. 2007 Jul;92(7):2744-50.

18 Rance NE, Young WS 3rd. Hypertrophy and increased gene expression of neurons containing neurokinin- $\mathrm{B}$ and substance-P messenger ribonucleic acids in the hypothalami of postmenopausal women. Endocrinology. 1991 May;128(5):2239-47. 
19 Abel TW, Voytko ML, Rance NE. The effects of hormone replacement therapy on hypothalamic neuropeptide gene expression in a primate model of menopause. J Clin Endocrinol Metab. 1999 Jun;84(6):2111-8.

20 Cholanian M, Krajewski-Hall SJ, McMullen NT, Rance NE. Chronic oestradiol reduces the dendritic spine density of KNDy (kisspeptin/ neurokinin $\mathrm{B} /$ dynorphin) neurones in the arcuate nucleus of ovariectomised Tac2-enhanced green fluorescent protein transgenic mice. J Neuroendocrinol. 2015 Apr;27(4):253-63.

21 Morrison SF, Nakamura K. Central neural pathways for thermoregulation. Front Biosci (Landmark Ed). 2011 Jan;16:74-104.

22 Shughrue PJ, Lane MV, Merchenthaler I. In situ hybridization analysis of the distribution of neurokinin-3 mRNA in the rat central nervous system. J Comp Neurol. 1996 Aug; 372(3):395-414.

23 Mittelman-Smith MA, Williams H, Krajewski-Hall SJ, McMullen NT, Rance NE. Role for kisspeptin/neurokinin B/dynorphin (KNDy) neurons in cutaneous vasodilatation and the estrogen modulation of body temperature. Proc Natl Acad Sci USA. 2012 Nov; 109(48): 19846-51.

24 Dacks PA, Rance NE. Effects of estradiol on the thermoneutral zone and core temperature in ovariectomized rats. Endocrinology. 2010 Mar;151(3):1187-93.

25 Sandoval-Guzmán T, Rance NE. Central injection of senktide, an NK3 receptor agonist, or neuropeptide Y inhibits LH secretion and induces different patterns of Fos expression in the rat hypothalamus. Brain Res. 2004 Nov; 1026(2):307-12.

26 Dacks PA, Krajewski SJ, Rance NE. Activation of neurokinin 3 receptors in the median preoptic nucleus decreases core temperature in the rat. Endocrinology. 2011 Dec;152(12): 4894-905.

27 Krajewski-Hall SJ, Blackmore EM, McMinn JR, Rance NE. Estradiol alters body temperature regulation in the female mouse. Temperature (Austin). 2017 Nov;5(1):56-69.

28 Jayasena CN, Comninos AN, Stefanopoulou E, Buckley A, Narayanaswamy S, Izzi-Engbeaya C, et al. Neurokinin B administration induces hot flushes in women. Sci Rep. 2015 Feb;5(1):8466.
29 Crandall CJ, Manson JE, Hohensee C, Horvath $\mathrm{S}$, Wactawski-Wende J, LeBlanc ES, et al. Association of genetic variation in the tachykinin receptor 3 locus with hot flashes and night sweats in the Women's Health Initiative Study. Menopause. 2017 Mar;24(3):252-61.

30 Prague JK, Dhillo WS. Treating hot flushes with a neurokinin 3 receptor antagonist. Oncotarget. 2017 Nov;8(63):106153-4.

31 Prague JK, Roberts RE, Comninos AN, Clarke S, Jayasena CN, Nash Z, et al. Neurokinin 3 receptor antagonism as a novel treatment for menopausal hot flushes: a phase 2, randomised, double-blind, placebo-controlled trial. Lancet. 2017 May;389(10081):1809-20.

32 Prague JK, Roberts RE, Comninos AN, Clarke $\mathrm{S}$, Jayasena CN, Mohideen P, et al. Neurokinin 3 receptor antagonism rapidly improves vasomotor symptoms with sustained duration of action. Menopause. 2018 Aug;25(8): 862-9.

33 Skorupskaite K, George JT, Veldhuis JD, Millar RP, Anderson RA. Neurokinin 3 Receptor Antagonism Reveals Roles for Neurokinin B in the Regulation of Gonadotropin Secretion and Hot Flashes in Postmenopausal Women. Neuroendocrinology. 2018;106(2):148-57.

34 Depypere H, Timmerman D, Donders G, Sieprath P, Ramael S, Combalbert J, et al. Clinical evaluation of the NK3 receptor antagonist fezolinetant (a.k.a. ESN364) for the treatment of menopausal hot flashes. Maturitas. 2017 Sep;103:89-90.

35 Pawsey S, Ballantyne E, Trower M, Kerr M. NT-814, a novel dual NK1,3 receptor antagonist results in immediate improvements in bothersome post-menopausal symptoms. In: North American Menopause Society (NAMS) Annual Meeting. 2018.

36 National Center for Biotechnology Information. Fezolinetant (ESN364). PubChem Compound Database; $\mathrm{CID}=117604931$ [cited November 9, 2018]. Available from: https:// pubchem.ncbi.nlm.nih.gov/compound/ 117604931.

37 National Center for Biotechnology Information. Pavinetant (MLE4901). PubChem Compound Database; CID=23649245 [cited November 9, 2018]. Available from: https:// pubchem.ncbi.nlm.nih.gov/compound/ 23649245.
38 Fraser GL, Hoveyda HR, Clarke IJ, Ramaswamy S, Plant TM, Rose C, et al. The NK3 Receptor Antagonist ESN364 Interrupts Pulsatile LH Secretion and Moderates Levels of Ovarian Hormones Throughout the Menstrual Cycle. Endocrinology. 2015 Nov; 156(11): 4214-25.

39 Fraser GL, Ramael S, Hoveyda HR, Gheyle L, Combalbert J. The NK3 Receptor Antagonist ESN364 Suppresses Sex Hormones in Men and Women. J Clin Endocrinol Metab. 2016 Feb;101(2):417-26.

40 Skorupskaite K, George JT, Veldhuis JD, Millar RP, Anderson RA. Interactions Between Neurokinin B and Kisspeptin in Mediating Estrogen Feedback in Healthy Women. J Clin Endocrinol Metab. 2016 Dec;101(12):462836.

41 Skorupskaite K, George JT, Veldhuis JD, Anderson RA. Neurokinin B regulates gonadotropin secretion, ovarian follicle growth, and the timing of ovulation in healthy women. J Clin Endocrinol Metab. 2018 Jan;103(1):95104.

42 George JT, Kakkar R, Marshall J, Scott ML, Finkelman RD, Ho TW, et al. Neurokinin B Receptor Antagonism in Women With Polycystic Ovary Syndrome: A Randomized, Placebo-Controlled Trial. J Clin Endocrinol Metab. 2016 Nov;101(11):4313-21.

43 Trower MK, Ratti E, Burgess C, Kerr MB. P-58. Evidence for rapid and sustained target engagement by a dual mechanism neurokinin-3,1 receptor antagonist on hypothalamic KNDy neurons; results from phase 1 studies with NT-814, a potential novel therapy for sex hormone-dependent diseases. In: The 3rd World Conference on Kisspeptin. 2017.

44 Ridler K, Gunn RN, Searle GE, Barletta J, Passchier J, Dixson L, et al. Characterising the plasma-target occupancy relationship of the neurokinin antagonist GSK1144814 with PET. J Psychopharmacol. 2014 Mar;28(3): 244-53.

45 Patil T, Bernard B. Complications of Androgen Deprivation Therapy in Men With Prostate Cancer. Oncology (Williston Park). 2018 Sep;32(9):470-4. 